\title{
БЕЗЛИЧНЫЕ ПРЕДЛОЖЕНИЯ В РУССКОМ И НОРВЕЖСКОМ ЯЗЫКАХ
}

\author{
ОльгА КлоновА \\ Мурманский гуманитарный институт
}

\section{АннотАция}

В статье рассматриваются способы передачи безличных предложений при переводе художественных текстов с русского на норвежский язык на основе двуязычного корпуса РуН, включающего параллельные тексты на русском и норвежском языках. Примеры из корпуса показывают, что, несмотря на отсутствие прямых аналогий в русском и норвежском языках, существует ряд языковых особенностей, позволяющих говорить о соответствиях и о том, что русские и норвежские безличные предложения образуют пересекающиеся, но не совпадающие полностью классы.

\section{[1] ВВЕДЕНИЕ}

Безличные предложения в русском языке привлекают внимание исследователей достаточно долгое время, они рассматривались с разных подходов: формально-логического (А. А. Потебня, А. А. Шахматов), коммуникативного (В. Г. Гак, Г. А. Золотова), культурологического (А. Вежбицкая, Н. Д. Арутюнова) и др. Тем не менее, вопрос не теряет актуальности и на сегодняшний день по нескольким причинам: во-первых, расширение употребления этого типа синтаксических конструкций в современном русском языке (М. В. Захарова); во-вторых, неоднородность самого класса «безличных предложений» (БП); втретьих, специфичность соотношения между формальной и семантической организацией этого типа предложений.

Настоящее исследование проведено на основе контрастивно-переводческого метода с использованием параллельного русско-норвежского корпуса. Мы исходим из положений функционально-коммуникативной грамматики, а также некоторых понятий теории перевода. Интерес представляют способы передачи значений безличности на норвежский язык, в котором эта категория представлена гораздо менее разнообразным инвентарем средств. Кроме этого, нас интересует соотношение между способами выражения безличности в обоих языках. 
[2] БЕЗЛИЧНЫЕ ПРЕДЛОЖЕНИЯ В РУССКОМ ЯЗЫКЕ

Как известно, безличные предложения в русском языке составляют большую неоднородную группу (см. обзор литературы по категории безличности и безличным предложениям в Петров 2007). Приведем определение, данное в указанной монографии: БП - «бесподлежащная синтаксическая конструкция со сказуемым в безличной форме, выражающая независимое от активного деятеля действие или независимое от носителя состояние» (Петров 2007, 46). В этом определении сведены основные признаки БП, упоминаемые в литературе, поэтому примем его как наиболее исчерпывающее и емкое.

Заметим, однако, что понятие «безличное» по отношению к сказуемому не всегда означает отсутствие лица или деятеля. Здесь необходимо вспомнить широко цитируемую мысль А. А. Потебни о том, что «в понятие глагола непременно входит отношение к лицу, каково бы ни было это последнее: известное или неизвестное, действительное или фиктивное. Под безличностью глагола давно привыкли понимать не отсутствие грамматического лица, а известные его свойства» (Потебня 1958, 91). Мысль всегда двучленна, «о чем-то сообщается что-то, некоторому субъекту приписывается некий предикативный признак» (Золотова 2007, 24), поэтому любое предложение содержит скрыто или явно - два элемента, «организующих центра», «предикативный признак и предицируемый признак» (там же). Скрытым субъектом в БП выступает окружающая среда или состояние человека: информация о нем заключается в самих глагольных лексемах, например, «Моросит»; «Распогодилось»; «Не здоровится» (Георгиев 1990, 13; см. тж. Бондарко 1991, 24).

В БП на первый план выдвигается действие или состояние, деятель или каузатор состояния затушевывается, даже если он и упоминается в самом предложении («Ветром снесло плотину»); таким образом, в фокусе внимания оказывается рематический компонент, и предложения становятся экономнее личных - что считается одной из причин распространения этого типа конструкций в русском языке (Тарланов 1999, 93, 99).

Кроме этого, часть БП связывается со стихийными силами, неподвластными человеку (Арутюнова 1999), - что, как принято думать, хорошо укладывается в традиционную для русского национального сознания схему и также способствует активизации употребления этих конструкций.

Основные функции БП - описание состояния природы или человека, отсутствие чего-либо (Суй Сюебэнь 2004), стихийных явлений природы, организма, внутреннего мира человека, модальность, значения существования (Ю. С. Степанов). Формой выражения предикативного члена БП могут быть следующие (Валгина 2001):

(i) Безличные глаголы («Морозило», «Вечереет») 
(ii) Личные глаголы в безличном употреблении или безличные значения личных глаголов («Стихло»), в том числе т.н. безлично-пассивные формы («Не работается»)

(iii) Страдательные причастия в краткой форме («Было забыто»)

(iv) Безлично-предикативные слова (слова категории состояния) («Становится тепло»)

(v) Конструкции, выражающие отрицание («Счету нет столетьям»)

\section{[3] БЕЗЛИЧНЫЕ ПРЕДЛОЖЕНИЯ В НОРВЕЖСКОМ ЯЗЫКЕ}

Что касается безличности в норвежском языке, принято определять как безличные предложения предложения с формальным и «мнимым» подлежащим DET $^{1}$ (Faarlund et al. 2006, 679). Существует несколько структурных типов БП с формальным подлежащим, в число которых включаются, помимо предложений с безличным глаголом/глаголом в безличном употреблении, и предложения с глаголом в страдательном залоге, а также сочетания связки и прилагательного/существительного (Стеблин-Каменский 2006, 184-185). К основным сферам применения такого типа предложений можно гипотетически отнести, с опорой на данные первого из упомянутых грамматических справочников, следующие случаи:

(i) Описание метеорологических явлений (Det regner «Идет дождь», Det blåste friskt «Дул свежий ветер»).

(ii) Описание состояния окружающей среды (Det var kaldt «Было холодно») и отдельных событий, явлений, предметов (Det er dårlige tider «Плохие времена», Det er ikke jaktvær i dag «Сегодня не охотничья погода»)

(iii) Неизвестность субъекта действия, в том числе при пассиве (Det var bakt brød «Был испечен хлеб»; Det banker på døra «В дверь стучат»²). В последнем случае предложения с формальным подлежащим приближаются «К неопределенно-личным предложениям, в которых подлежащим являются неопределенные местоимения en или man» (СтеблинКаменский 2006).

Кроме этого, в литературе встречаются упоминания о том, что норвежские конструкции с det используются для выражения существования или местоположения (цит. по Sveen 1996, 93). Однако в упомянутой работе автор считает этот взгляд слишком узким и представляющим собой скорее «центр»

\footnotetext{
${ }^{1}$ В данном случае имеется в виду одна из разновидностей норвежского языка - букмол (т.н. «восточный» вариант), доминирующий во многих аспектах в Норвегии. В других диалектах этот элемент может иметь форму der или her (Sveen 1996, 98).

2 Примеры взяты из обоих цитируемых справочников.
} 
всего спектра данных явлений, а также высказывает предположение, что эти конструкции могут быть использованы только с непереходными глаголами т.е. обусловленность их использования может быть не семантическая, а грамматическая (там же, 6, 94 и др.).

Отдельным случаем использования $\operatorname{det}$ являются предложения с т.н. «мнимым подлежащим» (Стеблин-Каменский 2006, 185; presenteringssetninger в норвежской терминологии - Faarlund et al. 2006, 680): Det kom ein ny elev i klassa «В классе появился новый ученик». В этом случае реальный субъект действия «оттесняется» со своего места служебным словом det, эта необычная синтаксическая позиция формального дополнения выдвигает субъект действия на первый план, вследствие чего такие предложения используются, главным образом, для выделения (представления) нового элемента текста (Faarlund et al. 2006, 828).

Конструкции этого типа также предполагают дополнение только в неопределенной форме, причем подобное расположение субъекта действия отличает его от субъекта в позиции подлежащего. Так, предложения Det sover en student i parken «В парке спит студент» и En student sover i parken «Студент спит в парке» различны тем, что в первом случае имеется в виду какой-то студент (хотя и неопределенный), и толкование этого предложения может быть только конкретным, а во втором - интерпретация может быть как конкретной, так и более общей (Sveen 1996, 143). Это позволяет избегать подлежащего в неопределенной форме, чем цитируемый автор объясняет распространенность конструкций с «мнимым подлежащим» det в современном норвежском языке.

\section{[4] МАТЕРИАЛ}

Настоящее исследование проведено на основе корпуса РуН, содержащего русские и норвежские художественные (в основном) тексты и их перевод на норвежский и русский язык соответственно. Поиск в корпусе осуществлялся по морфологическим показателям (по форме безличных глаголов - 3 л. ед. ч. наст. вр., ср. р. ед. ч. прош. вр., слова состояния на -о), а также полексемно (вследствие ограниченности семантического диапазона БП, ограничены и лексические средства выражения, что позволяет составить конечный список (см., например, Суй Сюебэнь 2004; Петров 2007) и проводить поиск в корпусе по корню или конкретным словам). Кроме этого, полексемный поиск осуществлялся и в качестве дополнительного средства, о чем будет сказано ниже.

Примеры из русской литературы (Б. Акунин, М. Булгаков, Б. Пильняк, Л. Н. Толстой, Л. Улицкая, А. Чехов и др.) и их переводы на норвежский язык были проанализированы с учетом синтаксического окружения, доминирования роли (деятеля/экспериенцера), известности/неизвестности деятеля из (предыдущего) контекста, семантики глагола и ряда других факторов. Кроме 
этого, мы прибегали и к анализу переводов норвежских текстов на русский язык для дополнительной информации по функционированию норвежских БП. Корпус позволяет проанализировать практически все названные выше типы БП. Здесь мы, тем не менее, ограничимся несколькими, самыми репрезентативными, группами БП во избежание чрезмерного удлинения повествования. Кроме этого, из тех же самых соображений (а также потому, что русский язык располагает гораздо более обширным спектром рассматриваемых конструкций) больше внимания уделим русско-норвежским соответствиям, чем наоборот.

Основными вопросами для данной статьи являются следующие: 1) каким образом возможен перевод БП/передача русских БП на норвежском языке? и - шире - 2) как соотносится употребление безличных конструкций в норвежском и русском языках?

[5] СОПОСТАВЛЕНИЕ БП в РУССКОМ И НОРВЕЖСКОМ ЯЗЫКАХ

Рассмотрим способы перевода упомянутых выше групп БП.

\section{[5.1] Безличные глагольь}

Безличные глаголы, или «абсолютно-бессубъектные» (Д. Н. Овсянико-Куликовский), обозначающие состояние окружающей среды, переводятся практически всегда конструкциями с формальным det:

(1) Уже рано смеркалось. (А. Чехов)

Det begynte alt å bli tidlig mørkt.

(2) Рассвело; положение больного было то же. (Л. Толстой)

Det lysnet av dag; situasjonen for den syke var den samme.

Более того, при анализе примеров бросается в глаза то, что эта конструкция очень часто выбирается независимо от русского оригинала, т.е. норвежский язык предпочитает безличные конструкции с формальным DET, когда речь идет об атмосферных явлениях, как, например, в следующих случаях:

(3) Под утро поднялся ветер, и у Медеи сильно разболелась голова.

(Л. Улицкая)

Utpå morgenkvisten begynte det å blåse, og Medea fikk kraftig hodepine.

(4) Сегодня душно, где-то идет гроза. (М. Булгаков)

Det er lummert i dag, det blir nok uvoer.

Для более последовательного доказательства этой мысли проведем небольшой эксперимент со словом «дождь», сопоставив русскую и норвежскую части корпуса для выявления взаимо(не)зависимости конструкций и 
возможного влияния языка оригинала на структуры перевода. Из всех предложений русскоязычной части корпуса, в которых встречается этот элемент, в 76 предложениях «дождь» выступает в качестве подлежащего/субъекта действия при личном глаголе в активном залоге, что является типичным употреблением для русского языка. В норвежской части им соответствуют 16 предложений с похожей структурой, причем только 4 из них встречаются в оригинальных произведениях:

(5) Regnet pisket og vinden raste. (J. Wiese)

Вовсю хлестал дождь и свирепствовал ветер.

(6) Duskregnet tuslet over taket. (Н. Wassmo)

По крыше барабанил дождь.

(7) Regnet hadde løyet. (H. Wassmo)

Дождь временно затих.

Остальные 12 - в переводах с русского языка, где подобная структура или соответствует изначальной русской или указывает на стремление сохранить образность оригинала, но в любом случае вызвана художественными, стилистическими целями, поскольку является частью тропа:

(8) Похолодало, пошел темный дождь, обещавший обернуться снегом.

(л. Улицкая)

Det ble kaldere, og et mørkt regn passerte med tydelig løfte om å gå over til snø.

(9) Снова начинал сеять дождь ... сперва тихо, осторожно, потом все гуще и, наконец, превращался в ливень с бурей и темнотою. (И. Бунин)

Igjen begynte regnet å dryppe ... til å begynne med stille og forsiktig, så tettere og tettere, for tilslutt å gå over i stormende, mørkt styrtregn.

В двух случаях в норвежском варианте конструкция пассивная - дождь выступает каузатором некоторого состояния:

(10) Дождь мочил его сено. (Л. Толстой)

Høyet var blitt vått i regnet.

(11) De ble overrasket av regn. (N. Frobenius)

В пути их застал дождь.

Остальные 60 предложений в норвежской выборке-безличные с формальным подлежащим det, независимо от того, оригинальный это норвежский текст или перевод. Похожие результаты дает сопоставление других «атмосферных» слов, с незначительными колебаниями цифр. Таким образом, мы можем сделать вывод о частичном влиянии языка оригинала на выбор кон- 
струкции при переводе, и, что для нас важнее, - о том, что в подавляющем большинстве случаев для атмосферных явлений в норвежском языке используются безличные предложения. С одной стороны, это объясняется строем норвежского языка, предполагающего обязательную двучленность конструкции даже в тех случаях, когда субъект неизвестен, с другой-наводит на мысль о том, что эти явления воспринимаются как стихийные, имеющие неизвестный источник и в гораздо меньшей степени, чем в русском языке, имеющие тенденцию выступать в качестве активного деятеля - даже в том случае, если этой действие налицо и есть результат действия, ими вызванного.

\section{[5.2] Безличные значения личных глаголов}

В отличие от первой группы БП, примеры из корпуса не позволяют вывести какие-либо общие тенденции перевода этой группы. Можно отметить следующее: при отсутствии «каузатора» действия при переводе на норвежский язык используются безличные конструкции, как с формальным, так и с «мнимым» det, а также пассивный залог; в случае если таковой известен, то конструкция передается активным залогом, при этом каузатор действия ставится на место подлежащего. При этом большая часть из проанализированных примеров указывает на то, что при описании стихийных явлений окружающей среды предпочитается БП, для остальных - пассивный залог.

$Б \Pi \rightarrow Б \Pi$

(12) На подоконнике намело маленькую неровную горку снега.

(Л. Улицкая)

I vinduskarmen hadde det hopet seg opp en ujevn liten haug med snø.

(13) Потом вдруг, на второй день Святой, понесло теплым ветром, надвинулись тучи, и три дня и три ночи лил бурный и теплый дождь.

(Л. Толстой)

Men så plutselig annen påskedag blåste det opp en varm vind, skyene trakk seg sammen, og tre dager og tre netter silte det varme regnet ned.

(14) Холодом веяло от них. (М. Булгаков)

Det strømmet en kulde ut fra dem.

БП $\rightarrow$ пассивньй залог

(15) Странную тучу принесло с моря к концу дня, четырнадцатого дня весеннего месяца нисана. (М. Булгаков)

Den selsomme skyen var blitt ført inn fra havet mot slutten av den fjortende dag i vårmåneden nisan. 
(16) Тех, кто вторым поколением возрастал после Катерины Ивановны, $u x$ разметало по всей земле, не только русской. (Б. Пильняк)

De som vokste opp som 2. generasjon etter Katerina Ivanovna ble spredt over hele jordkloden, ikke bare i Russland.

(17) Мачту занесло под ахтерштевень, тросы замотались вокруг руля.

(Б. Пильняк)

Masten ble fort under akterstavnen, trossene viklet seg rundt roret.

(18) По дорогам была непролазная грязь; две мельницы снесло паводком, и погода все становилась хуже и хуже. (Л. Толстой)

Veiene forsvant i bunnløs gjørme; to møller ble tatt av flommen, og været ble bare verre og verre.

(19) ...там, где стояли баржи и толпились тысячи, ничего не было, и забойку размыло водой. (Б. Пильняк)

...der hvor elveprammer hadde ligget og tusenvis hadde flokket seg var det nå ingenting, og bryggen var skylt bort av vannet.

БП $\rightarrow$ активный залог

(20) Дошел до середины моста и бросился в воду: чудом спасся; нанесло его водой на старый бык, оставшийся от прежнего моста. (Б. Пильняк) Han gikk midt ut på broen og kastet seg i vannet, ved et under reddet han seg; vannet forte ham til den gamle bropillaren som sto igjen etter den tidligere broen.

(21) ...огромной волной снесло все снасти и даже перила (Л. Цыпкин) ...en kolossal bølge hadde spjœeret alt tauverk og til og med rekket.

Неагентивность как таковая не всегда получает выражение в норвежских переводах: стихийно представленное в русском языке действие может быть переведено активным залогом на норвежский язык - как представляется, это зависит от значения и употребления конкретного глагола норвежского языка, его сочетаемостных характеристик. В следующих примерах (22)-(24) норвежский текст теряет стихийность, независимость действия от воли человека, столь характерную для русских БП.

(22) А что же вас в Болгарию понесло? (Б. Акунин) Men hvorfor ville De til Bulgaria?

(23) Тогда Могарыча перевернуло кверху ногами и вынесло из спальни Воланда через открытое окно. (М. Булгаков)

Dermed gjorde Mogarytsj kollbøtte ut gjennom Wolands åpne soveværelsesvindu. 
(24) Машину занесло, ударился об ручку двери, - ответил Варенуха, отводя глаза. (М. Булгаков)

Bilen skrenset, jeg slo meg mot dørhåndtaket, svarte Varenucha og så bort.

Особую роль этот компонент значения играет в романе М. Булгакова «Мастер и Маргарита», из которого взяты предложения (23) и (24): сверхъестественные силы управляют всем действием и всеми персонажами романа, отчего возникает ощущение нереальности происходящего, поэтому БП приобретают дополнительную стилистическую окраску - писателю важно показать «не отдельно человека и стихийные силы, а именно человека, живущего и действующего под властью стихийных, сверхъестественных, судьбоносных сил» (Башкирова 2008, 15). В связи с этим (хотя пример (24) демонстрирует словарный эквивалент соответствующей русской фразы) представляется, что синтаксис перевода утрачивает свою стилистическую нагрузку.

Отдельного внимания заслуживают возвратно-безличные формы, получающие все большее распространение в современном русском языке (Петров 2007; Захарова 2004 и др.). Чаще всего эти формы переводятся соответствующими глаголами (при этом субъект необходимо становится подлежащим):

(25) Мне всегда как-то лучше работается за городом. (М. Булгаков) Jeg arbeider likesom alltid best på landet.

(26) Да ведь это бред, ведь я знаю! - думалось ему... (Ф. Достоевский) Men dette er jo feberfantasier, det vet jeg jo! tenkte han...

(27) Хотелось уйти, но было неловко перед Медеей. (Л. Улицкая)

Hun ville helst ha gått, men syntes det var flaut overfor Medea.

Гораздо реже в переводе используются другие конструкции, в том числе безличные - как можно предположить, этот выбор в переводе предполагает необходимость подчеркнуть независимость протекания действия от воли человека. Устранение собственно субъекта действия переносит акцент на само действие, и ситуация преподносится как данность, что в целом соответствует по значению русским БП:

(28) «Зачем он сидел в этой распивочной?» - все думалось ему. (Ф. Достоевский)

"Hvorfor satt han i den skjenkestuen?" surret det hele tiden i tankene hans.

(29) Первое время ей не читалось. (Л. Толстой)

Til å begynne med ble det ingen greie på lesningen.

Эти примеры, хоть и малочисленные, показывают, что в отдельных случаях русские и норвежские БП используются для идентичных целей рема- 
тизации непосредственно действия и представления ситуации как относительно свободной от желания человека.

В следующем примере мы видим подлежащную конструкцию, в которой подлежащим становится само действие, что допускает интерпретацию, аналогичную вышеприведенной - переводчику важно сохранить тот оттенок смысла, который передается русским БП:

(30) И писалось ему в этот день легко. (А. Курков)

Og skrivingen gikk lett denne dagen.

Если повторить эксперимент, описанный выше, и посмотреть на употребление норвежских БП независимо от перевода с русского или на русский язык, то корпус позволяет сказать следующее. Модель Det+V проявляет тенденцию использоваться с конкретными глаголами: движения (о людях, времени), skrive, stå (быть написанным), глаголами звука (ringe) и ощущения (dukte, lufte), интеллектуальных/мыслительных процессов (slå, minne) ${ }^{3}$ - т.е. имеет большую отнесенность к определенным сферам; также можно проследить параллели с соответствующими сферами в русском языке, хотя эти результаты предварительны и нуждаются в дальнейшей разработке.

(31) Det gikk et slags lys opp for David. (E. F. Hansen)

Давид начал кое-что понимать.

(32) Det virket som om Spot bare hadde ventet på stikkord. (Е. F. Hansen)

Спот словно только этого и ждал.

Другой закономерностью является коммуникативная функция порядка слов в БП, отличающегося от порядка слов в личных предложениях, что подтверждает приведенную выше цитату об использовании БП с «мнимым» подлежащим для выделения части текста и представления новой информации:

(33) Det satt tre menn i kupéen (E. F. Hansen)

В купе уже сидели три человека.

(34) Og hvis det kommer post, åpner jeg den og faxer. (Е. Loe)

Если приходит почта, вскрываю конверты и пересылаю письма брату по факсу.

Остальные две группы БП русского языка не обнаруживают, во-первых, параллелей в использовании норвежских БП, во-вторых, редко обнаруживают

${ }^{3}$ А. Свеен считает, однако, что для использования в подобной функции глагол должен выражать «заметное, легко воспринимаемое событие или действие»; поэтому функционирование глаголов, выражающих интеллектуальные процессы, в конструкциях с det очень ограничено и является скорее маргинальным, чем типичным явлением (Sveen 1996, 104-105). 
вообще какие-либо закономерности перевода. Приведем несколько примеров для иллюстрации этого тезиса.

\section{[5.3] Конструкции со страдательными причастиями в краткой форме}

Конструкции со страдательными причастиями в краткой форме не имеют общей синтаксической схемы в переводе; во всех примерах способ перевода выбирается в зависимости от синтаксического контекста, перспективы повествования, эмоциональной нагрузки и других факторов.

В следующих примерах одна и та же лексема по-разному интерпретируется при переводе:

(35) Кроме того, из этого же оказывалось, что бороны и все земледельческие орудия, которые велено было осмотреть и починить еще зимой и для которых нарочно взяты были три плотника, были не починены, и бороны все-таки чинили, когда надо было ехать скородить.

(Л. Толстой)

Av dette fremgikk det videre at harvene og all redskapen han hadde gitt ordre om å gå over og reparere alt i vinter, og som han hadde festet tre snekkere til å ta seg av, ikke var brakt i orden og harvene reparerte de fremdeles på, enda det var på tide å dra ut og harve.

(36) Сторожам велено было посыпать пол песком. (Б. Пильняк) Vaktene ble beordret å strø gulvet med sand.

(37) - Мне, - говорит, - его разбить велено и оскретки в реку бросить. (Л. Толстой)

“Jeg er blitt pålagt å slå den i stykker og kaste bitene i elva."

(38) Это была религия возвышенная, таинственная, связанная с рядом прекрасных мыслей и чувств, в которую не только можно было верить, потому что так велено, но которую можно было любить.

(Л. Толстой)

Dette var en opphøyet, hemmelighetsfull religion, forbundet med en hel rekke skjønne tanker og følelser, og man måtte ikke nøye seg med å tro på den fordi man fikk ordre om det, nei, denne kunne man elske.

В этой группе примеров центральным при переводе оказывается направление волеизъявления, что отражено в выбранных моделях языка перевода: в (35) ситуация показана с точки зрения героя-источника волеизъявления, при этом БП можно рассматривать как один из способов передачи внутренней речи героя; примеры (36) и (37) ориентированы на конкретного, указанного в контексте адресата действия, в примере (38) адресат не определен, что подчеркивается неопределенно-личным местоимением man. 
Интересно также проследить, как на норвежский язык передаются авторские неологизмы, подобные (39). Их можно рассматривать как иллюстрацию безэквивалентности подобных конструкций:

- Свистнуто, не спорю, - снисходительно заметил Коровьев, - действительно свистнуто, но, если говорить беспристрастно, свистнуто очень средне! (М. Булгаков)

- Du har fløytet, jeg benekter ikke det, bemerket Korovjev nedlatende, jovisst har du fløytet, men om man skal se nøkternt på det, så var det et meget middelmådig fløyt!

Выше уже упоминалось о роли БП в романе М. А. Булгакова; здесь мы видим, что к основным функциям БП добавляется языковая игра, характерная для этих героев романа (т.е. собственно словотворчество на основе ключевой для романа модели). Перенос акцента с деятеля на действие, выраженное в причастии и подчеркнутое неоднократным повтором в разном синтаксическом окружении, в норвежском тексте оказывается актуализированным только в последнем случае.

\section{[5.4] Безлично-предикативные слова}

Безлично-предикативные слова (слова категории состояния) проявляют скорее лексико-семантические, нежели синтаксические параллели. Этот класс слов представляет собой очень большую и разнородную группу, включающие как описание состояния, так и оценку, модальное значение и др. Среди основных закономерностей можно выявить следующие:

(i) Состояние природы (атмосферы), окружающей среды, как уже было отмечено, обычно передается предложениями с формальным подлежащим det:

(40) В вагоне было очень светло. (Б. Пильняк) I vognen var det svært lyst.

(41) Поднимался ветерок, и стало серо, мрачно. (Л. Толстой) Det begynte så smått å blåse, og det ble grått og trist.

(42) Было тепло и курортно. (Л. Улицкая)

Det var varmt, og alt minnet om at dette var et kursted.

Последний пример интересен с точки зрения авторского неологизма «курортно», также являющегося безлично-предикатным словом: его перевод обусловлен передачей исключительно денотативного значения слова, что потребовало описания всей ситуации в переводе. 
(ii) Физическое или психическое состояние человека передается с помощью соответствующих прилагательных/наречий и глаголов ощущения/восприятия føle, synes и др.

(43) Ей так легко и спокойно было. (Л. Толстой) Hun følte seg så lett og rolig til sinns.

(44) Ей стало смешно и тотчас стыдно за то, что ей могло быть чтонибудь смешно в такую минуту. (Л. Толстой)

Hun syntes det var komisk, men ble straks skamfull over at hun kunne synes noe var komisk i en stund som denne.

(iii) Слова, имеющие модальное значение (не)возможности/необходимости/целесообразности (нужно, можно, нельзя и др.), как правило, передаются соответствующими модальными глаголами, при этом субъект, необходимый в норвежском предложении, зависит от контекста, в данных примерах - неопределенного (без указания на конкретное лицо) или определенного (в котором лицо подразумевается в контексте):

(45) Надо было придумывать опять новую тему. (Л. Толстой) Man måtte tenke ut et nytt emne.

(46) Надо было прожить еще по крайней мере два часа. (Л. Толстой) Han måtte holde ut minst to timer til.

\section{[6] Выводы}

Таким образом, сопоставляя русские БП и их перевод на норвежский язык, можно отметить несколько тенденций. Следуя вопросам, поставленным в начале статьи, сделаем два основных вывода.

Во-первых, в переводе БП обнаруживаются, прежде всего, лексические и семантические соответствия (учитывая стремление переводчика передать смысл оригинала - т.е. предпочтение семантического способа перевода), и только в последнюю очередь-синтаксические. Можно даже сказать, что параллели в синтаксисе прослеживаются очень редко: во многом рассмотренные русские БП принадлежат к т.н. «безэквивалентным» конструкциям, вследствие чего при переводе текста на норвежский язык используются другие способы передачи соответствующих значений, не без смысловых потерь. Одним из самых распространенных способов является подбор словарного соответствия или слова/фразы, близких по значению. Неизбежные синтаксические замены чаще всего принимают форму своеобразных «манипуляций» с основными компонентами фразы - субъектом/каузатором действия и экспериенцером этого действия, которые могут менять синтаксические позиции в 
переводе, в зависимости от контекста, стилистических характеристик и других факторов.

Во-вторых, БП в русском и норвежском языках образуют пересекающие, но не совпадающие полностью классы: можно предполагать определенную степень лексической/семантической закрепленности (которая несколько различается в обоих языках, однако прослеживаются некоторые взаимные соответствия). Наблюдаются также тема-рематические закономерности при использовании БП: в обоих языках они акцентируют рематические элементы фразы.

\section{СПИСОК ЛИТЕРАТУРЫ}

Арутюнова, Н. Д. 1999. Язык и мир человека. М.: Языки русской культуры.

Башкирова, И. А. 2008. Безличные предложения в контексте романа М. А. Булгакова «Мастер и Маргарита». Автореферат дисс. ... канд. филолог. наук.

Бондарко, А. В. (ред.). 1991. Теория функциональной грамматики: Персональность. Залоговость. СПб.: Наука.

Валгина, Н. С. 2001. Синтаксис современного русского языка. М.: Агар.

Георгиев, И. 1990. Безличные предложения в русском и болгарском языках. София: Народна просвета.

Захарова, М. В. 2004. Об одной группе безличных глаголов (глаголы типа «спится») // А. В. Петров (ред.), Объект исследования - безличность, 36-40. Архангельск: Поморский университет.

Золотова, Г.А. 2007. Коммуникативные аспекты русского синтаксиса. М.: КомКнига.

Петров, А. В. (ред.). 2007. Безличность как семантико-грамматическая категория русского языка. Архангельск: Поморский университет.

Потебня, А. А. 1958. Из записок по русской грамматике. I-II. М.: Учпедгиз.

Стеблин-Каменский, М. И. 2006. Грамматика норвежского языка. М.: КомКнига.

Суй Сюебэнь. 2004. Категория безличности и безличные предложения в русской языковой картине мира. Автореферат дисс. ... канд. филолог. наук.

Тарланов, 3. К. 1999. Становление типологии русского предложения и ее отношение к этнофилософии. Петрозаводск: Издательство Петрозаводского университета.

Faarlund, Jan Terje, Svein Lie \& Kjell Ivar Vannebo (eds.). 2006. Norsk referansegrammatikk. Oslo: Universitetsforlaget. 
Sveen, Andreas. 1996. Norwegian impersonal actives and the Unaccusative Hypothesis. Dr. art. thesis, University of Oslo.

\author{
АДРЕС АВТОРА \\ Ольга Клонова \\ Мурманский гуманитарный институт \\ Кафедра германских языков и филологии \\ Мира 10-205, Мурманск \\ Россия \\ olgaklonova@hotmail.com
}

